Research Article

\title{
The Protective Effect of New Compound XH-103 on Radiation-Induced GI Syndrome
}

\author{
Yinping Dong $\left(\mathbb{D}\right.$, Ying Cheng $\mathbb{D}^{\mathbb{C}}$, Qinlian Hou, Jing Wu, Deguan Li $\mathbb{D}^{D}$, and Hongqi Tian $(\mathbb{D}$ \\ Tianjin Key Laboratory of Radiation Medicine and Molecular Nuclear Medicine, Institute of Radiation Medicine, Chinese Academy \\ of Medical Science and Peking Union Medical College, Tianjin 300192, China
}

Correspondence should be addressed to Deguan Li; lideguan@irm-cams.ac.cn and Hongqi Tian; tianhongqi@irm-cams.ac.cn

Received 12 March 2018; Revised 1 May 2018; Accepted 21 May 2018; Published 4 July 2018

Academic Editor: Kum Kum Khanna

Copyright (C) 2018 Yinping Dong et al. This is an open access article distributed under the Creative Commons Attribution License, which permits unrestricted use, distribution, and reproduction in any medium, provided the original work is properly cited.

\begin{abstract}
Background. Radiation-induced intestinal injury is one of the side effects in patients receiving radiotherapy. The aim of the present study was to investigate the protective effect of XH-103 on radiation-induced small intestinal injury and to explore its mechanism. Methods. C57BL/6N mice were irradiated and treated with XH-103. Firstly, the survival rate of mice exposed to $9.0 \mathrm{~Gy}$ and $11.0 \mathrm{~Gy}$ total body irradiation (TBI) was examined. Subsequently, at $3.5 \mathrm{~d}$ after IR, the small intestinal morphological changes were examined by HE. The numbers of crypt cells, the villus height, the expression of Ki67 and Lgr5, and the apoptotic cells in the intestinal crypts were examined by immunohistochemistry. Furthermore, the expression of p53 and Bax was analyzed by WB. Results. Compared to the irradiation group, $\mathrm{XH}-103$ improved the mice survival rate, protected the intestinal morphology of mice, decreased the apoptotic rate of intestinal crypt cells, maintained cell regeneration, and promoted crypt proliferation and differentiation. XH-103 also reduced the expression of p53 and Bax in the small intestine compared to the IR group. Conclusion. These data demonstrate that XH-103 can prevent radiation-induced intestinal injury, which is beneficial for the protection of radiation injuries.
\end{abstract}

\section{Introduction}

Currently, radiation therapy is widely used in a variety of cancer treatments. The small intestine is one of the most sensitive organs to ionizing radiation (IR) in the human body. High doses of ionizing radiation induce acute damage to epithelial cells of the intestines and produce death within 10 days reflecting toxicity to the gastrointestinal (GI) tract [1]. In contrast to radiation-induced bone marrow damage which can be prevented by bone marrow transplantation, there are no approved methods to prevent or treat radiation-induced gastrointestinal syndrome (RIGS) [2]. The main symptoms of radiation-induced intestinal damage include anorexia, vomiting, diarrhea, dehydration, systemic infection, and in extreme cases, septic shock and death [3]. Radiation-induced intestinal damages seriously affect the treatment of patients with abdominal or pelvic tumors, reducing the quality of life of patients. Therefore, the development of efficient radiological intestinal drugs is an important area of radiation protection.
Natural antioxidant agents and aminothiol compounds have been intensively investigated for the radiation protection application [4-6]. Flavonoids belong to natural antioxidant agents that can suppress the formation of free radicals and have antioxidant effects. However, it has disadvantage of poor stability and bioavailability [7]. Aminothiol compound possesses good efficacy profile but short half-life and high toxicity [8].

In this study, we take the natural antioxidation agent quercetin which belongs to flavonoid family derived from plants as a lead compound and modify the molecular structure. At the same time, we also try to combine the aminothiol analogue and the natural antioxidation agent together with different linkers in order to retain the efficacy of aminothiol and the safety property of natural antioxidation agent, respectively. The quercetin group and aminothiol group can modulate pharmacokinetic (PK) profile mutually. Finally, we designed and synthesized the compound TZ (XH-103) (Scheme 1). 


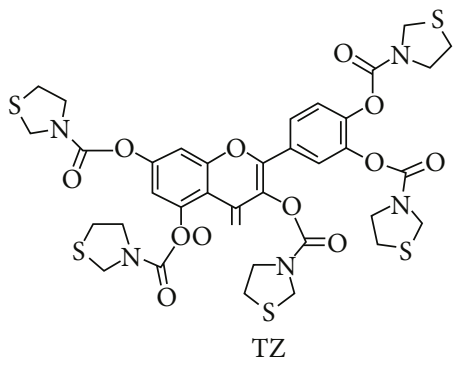

SCheme 1

In this study, to define the effect of $\mathrm{XH}-103$ on intestinal repair and regeneration following radiation injury, we used a mouse model of radiation-induced intestinal damage by exposure to $9.0 \mathrm{~Gy}$ total body irradiation (TBI). We found that the $\mathrm{XH}-103$ could improve the survival rate of mice and intestinal epithelium cells (IECs). We also found that the crypt-villous structure injuries of the small intestines and the apoptosis of IECs induced by TBI were mitigated by $\mathrm{XH}-103$. And $\mathrm{XH}-103$ could protect the proliferation and differentiation of intestinal stem cells (ISCs). Here, we evaluated the possibility and mechanisms of the radiation protective effects of XH-103 on radiation-induced intestinal injury.

\section{Materials and Methods}

2.1. Synthesis of Thiazolidine-3-carbonyl Chloride. To a solution of bis(trichloromethyl) carbonate $(4.79 \mathrm{~g}, 53.82 \mathrm{mmol})$ (Energy Chemical, Shanghai, China) in anhydrous tetrahydrofuran $(35 \mathrm{~mL})$ were added thiazolidine $(4 \mathrm{~g}$, $44.94 \mathrm{mmol}$ ) (Energy Chemical, Shanghai, China) in parts and triethylamine $(8.1 \mathrm{~mL})$ dropwise, the mixture was stirred under nitrogen atmosphere and in ice water bath for $1 \mathrm{~h}$ and then at room temperature for $10 \mathrm{~h}$. The reaction mixture was filtered, and the residue was washed with dichloromethane $(10 \mathrm{~mL})$ for three times. The filtrate phase was combined and evaporated in vacuo. The resultant residue was used directly for the next step.

2.2. Synthesis of 2-(3,4-Bis((thiazolidine-3-carbonyl)oxy)phenyl)4-oxo-4H-chromene-3,5,7-triyl Tris(thiazolidine-3-carboxylate). To a solution of 2-(3,4-dihydroxyphenyl)-3,5,7-trihydroxy$4 \mathrm{H}$-chromen-4-one (1.6 g, $5.3 \mathrm{mmol})$ (Shuya Chemical Science and Technology, China) in DMF $(30 \mathrm{~mL})$ were added triethylamine $(7 \mathrm{~mL}), 4$-dimethylaminopyridine (192 mg, $1.57 \mathrm{~mol}$ ), and thiazolidine-3-carbonyl chloride, the mixture was stirred under $0^{\circ} \mathrm{C}$ for $1 \mathrm{~h}$ and at room temperature for $10 \mathrm{~h}$. The reaction mixture was poured into $\mathrm{MeOH} / \mathrm{H}_{2} \mathrm{O} /$ DMSO 8/1.5/0.5 $v / v / v(500 \mathrm{~mL})$, and then water was added dropwise until the product precipitated. The residue was then filtered and washed with water $(20 \mathrm{~mL})$ for three times. The filter cake was then dried under vacuo to give the title compound as a yellow solid (3.35 g, 72\%): LC-MS: $R_{\mathrm{T}}=4.5 \mathrm{~min}$; $[\mathrm{M}+\mathrm{H}]^{+}=879.20$, calculated $878.99,{ }^{1} \mathrm{H}$ NMR $(400 \mathrm{MHz}$, DMSO) $\delta$ ppm 7.95-7.85 (m, 2H), $7.68(\mathrm{~s}, 1 \mathrm{H}), 7.58$ $(\mathrm{d}, J=8.3 \mathrm{~Hz}, 1 \mathrm{H}), 7.25(\mathrm{~s}, 1 \mathrm{H}), 4.58(\mathrm{dd}, J=52.9,22.8 \mathrm{~Hz}$, $10 \mathrm{H}), 3.97-3.65(\mathrm{~m}, 10 \mathrm{H})$, and $3.14(\mathrm{~d}, J=20.2 \mathrm{~Hz}, 10 \mathrm{H})$.
2.3. Animals. Male C57BL/6 mice (8-10 weeks) were purchased from Beijing HFK Bioscience Co. Ltd. (Beijing, China). Animals were bred in the certified animal facility in the Institute of Radiation Medicine (IRM) of Chinese Academy of Medical Sciences (CAMS).

2.4. Ethics Approval and Consent to Participate. All experimental procedures were carried out in accordance with the NIH Guidelines for the Care and Use of Laboratory Animals and were approved by the Institutional Animal Care and Use Committee of the Institute of Radiation Medicine (IRM), Chinese Academy of Medical Sciences (CAMS) (Permit Number 2017053). The animals were cared for in accordance with the dictates of the National Animal Welfare Law of China.

2.5. Irradiation and Treatment. The mice were exposed to ionizing radiation by using a ${ }^{137} \mathrm{Cs}$ source following an Exposure Instrument Gammacell-40 (Atomic Energy of Canada Lim, Chalk River, ON, Canada) at a dose rate of $1.0 \mathrm{~Gy} / \mathrm{min}$. The mice were exposed to $9.0 \mathrm{~Gy}$ and $11.0 \mathrm{~Gy}$ TBI in the survival experiments $(n=10)$.

In the remaining experiments, the animals were divided randomly into three groups $(n=5)$ : (a) control, (b) IR + vehicle, and (c) IR +103 , and received 9.0 Gy TBI. XH-103 was dissolved in 4\% DMSO; $96 \%$ of PEG400 was added after heating for a final concentration of $20 \mathrm{mg} / \mathrm{mL}$. Individual mice in the IR +103 group received a dose of $200 \mathrm{mg} / \mathrm{kg}$ $\mathrm{XH}-103$ administered by gavage 1 hour before irradiation. The mice of the groups control and IR + vehicle were treated with vehicle similarly to the procedure described for the $\mathrm{XH}-103$ treatment.

2.6. Histological Analysis. At three days after IR, the mice were sacrificed, and the small intestines were collected and stained with hematoxylin-eosin (H\&E) and analyzed under a microscope. For morphological analysis, six circular transverse sections were analyzed per mice in a blind manner from coded digital HE-stained photographs to measure the villi length and crypt number by using the ImageJ 1.37 software.

2.7. Immunohistochemistry Analysis. The $4 \mu \mathrm{m}$-thick sections of paraffin-embedded small intestine sections were dewaxed and rehydrated with citrate buffer. Then, the sections were boiled in $10 \mathrm{mM} / \mathrm{L}$ citrate buffer solution ( $\mathrm{pH} 9.0$ ) for antigen retrieval according to the standard procedures. After antigen retrieval, the sections were incubated with serum for $1 \mathrm{~h}$ at room temperature to block nonspecific antigen-binding sites and then with anti-Lgr5 antibody (1:50 dilution, Abcam, Cambridge, MA, USA), anti-Ki67 antibody (1:300 dilution, Novus a biotechne brand), anti-lysozyme (1:800 dilution, Abcam, Cambridge, MA, USA), or anti-villi (1:800 dilution, Abcam, Cambridge, MA, USA) overnight at $4^{\circ} \mathrm{C}$. Sections were then incubated in secondary antibody for $30 \mathrm{~min}$ at $37^{\circ} \mathrm{C}$. Positive cells were detected using DAB kit (SigmaAldrich). The images were captured, and positive staining was quantified objectively by the IPP software as described previously in a blinded fashion. 


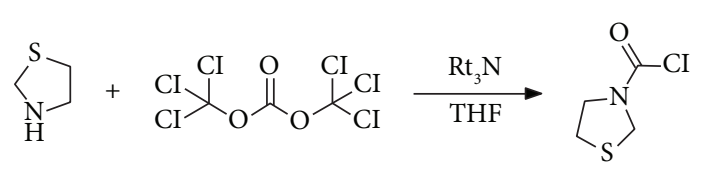

(a)

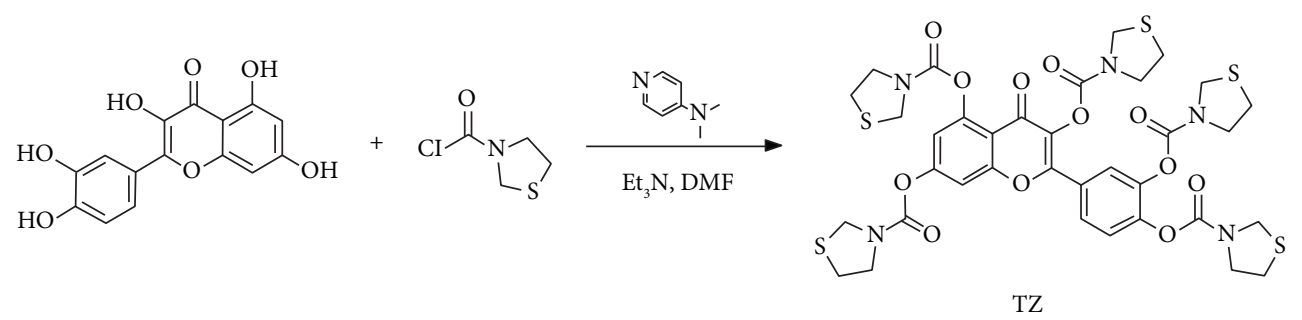

(b)

FIgURE 1: Synthesis and structure of TZ (XH-103). (a) The thiazolidine was reacted with bis(trichloromethyl) carbonate with triethylamine as base to prepare thiazolidine-3-carbonyl chloride. (b) Thiazolidine-3-carbonyl chloride was coupled with quercetin in the presence of triethylamine and 4-dimethylaminopyridine to afford the product TZ.

2.8. TUNEL Assay. The $3 \mu \mathrm{m}$-thick sections were treated according to the manufacturer's protocols (Roche, Mannheim, Germany). Sections were analyzed by light microscope.

2.9. Isolation of Intestinal Crypt Cells. The method of isolating intestinal crypts was described $[9,10]$. Briefly, after flushing with ice-cold PBS, the small intestines were chopped into small pieces and then placed into cold PBS containing $2 \mathrm{mM}$ EDTA for $30 \mathrm{~min}$. After rinsing twice with ice-cold PBS, the fragments were resuspended in cold dissociation buffer. The solution was filtered through a $70 \mu \mathrm{m}$ strainer to remove the villus fraction and collect the crypt fraction. The crypt fraction was centrifuged to isolate the single cells.

2.10. Western Blot Analysis. Protein was extracted from small intestinal crypt cells with ice-cold lysis buffer (Solarbio Science and Technology, Beijing, China). Protein concentration was quantified using the bicinchoninic acid protein assay kit (Beyotime, Shanghai, China), and equal amounts of protein were resolved by SDS-PAGE gel. The blocked membrane was incubated using anti-Bax antibody $(1: 1000$ dilution, Ruiying Bio, Suzhou, China) and antibodies against $\beta$-tubulin (1:2500 dilution, Proteintech, Wuhan, China) overnight at $4^{\circ} \mathrm{C}$. Then, the membranes were incubated in suitable horseradish peroxide-conjugated secondary antibody for 1-2 hours at room temperature. Finally, the chemiluminescent substrate (Millipore Corporation, Billerica, MA 01821, USA) is used to detect protein.

2.11. Immunofluorescence Analysis. The paraffin-embedded sections of the small intestine were subjected to antigen retrieval as described above and then washing thoroughly with PBS. The sections were blocked with $5 \%$ goat serum for $30 \mathrm{~min}$ at room temperature and then incubated with anti-caspase-8 (1:100 dilution, CST, MA, USA), anticaspase- 9 ( $1: 1000$ dilution, CST, MA, USA), anti- $\gamma \mathrm{H} 2 \mathrm{AX}$ ( $1: 1000$ dilution, BD biosciences, NJ, USA), and anti-p53 ( $1: 1000$ dilution, Ruiying Bio, Suzhou, China) overnight at $4^{\circ} \mathrm{C}$. After washing with PBS, the sections were incubated in the secondary antibody for $40 \mathrm{~min}$ at $37^{\circ} \mathrm{C}$ avoiding light. The sections were finally sealed with DAPI-containing sealing agent. The images were captured by laser scanning confocal microscope (LSCM).

2.12. Statistical Analysis. Mice survival curves were analyzed by Kaplan-Meier method using GraphPad Prism 6.0 software for Mac. The data were expressed as mean \pm standard deviation (SD). Analysis of variance (ANOVA) test was used to analyze differences among the groups, and $t$-test was used to analyze the difference between the two groups.

\section{Results}

3.1. Synthesis and Characterization of XH-103. Based on design concept, we designed and prepared the compound XH-103, of which the synthetic routes were shown in Figure 1. The synthetic procedures were depicted in Supplementary Materials (available here). Firstly, the thiazolidine was reacted with bis(trichloromethyl) carbonate with triethylamine as base to prepare thiazolidine-3-carbonyl chloride. Then, the as-prepared intermediate was further coupled with quercetin molecule in the presence of triethylamine and 4-dimethylaminopyridine to afford the 2-(3,4-bis((thiazolidine-3-carbonyl) oxy)phenyl)-4-oxo$4 \mathrm{H}$-chromene -3,5,7-triyl tris(thiazolidine-3-carboxylate) (XH-103) as products with the isolation yield of $72 \%$. The structure was characterized by NMR and ESI-MS. The ${ }^{1} \mathrm{H}$ NMR and ESI-MS spectrum of XH-103 is shown in Figures S1a and S1b. The results indicated that the new compound XH-103 was successfully prepared with facile synthetic approach.

3.2. XH-103 Improves the Survival Rate of Mice after TBI. To determine the protective effect of XH-103 on mice exposure to radiation, we first observed the survival rate of mice after 9.0 Gy TBI (Figure 2(a)). The mice were treated with XH-103 in three dosages $(100 \mathrm{mg} / \mathrm{kg}, 200 \mathrm{mg} / \mathrm{kg}$, and $400 \mathrm{mg} / \mathrm{kg}$ ); we found that all doses could improve the 


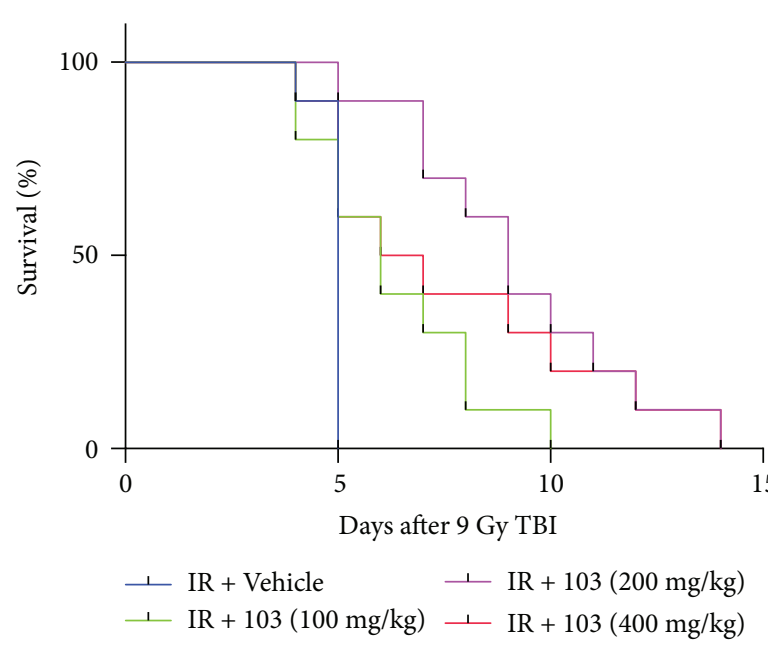

(a)

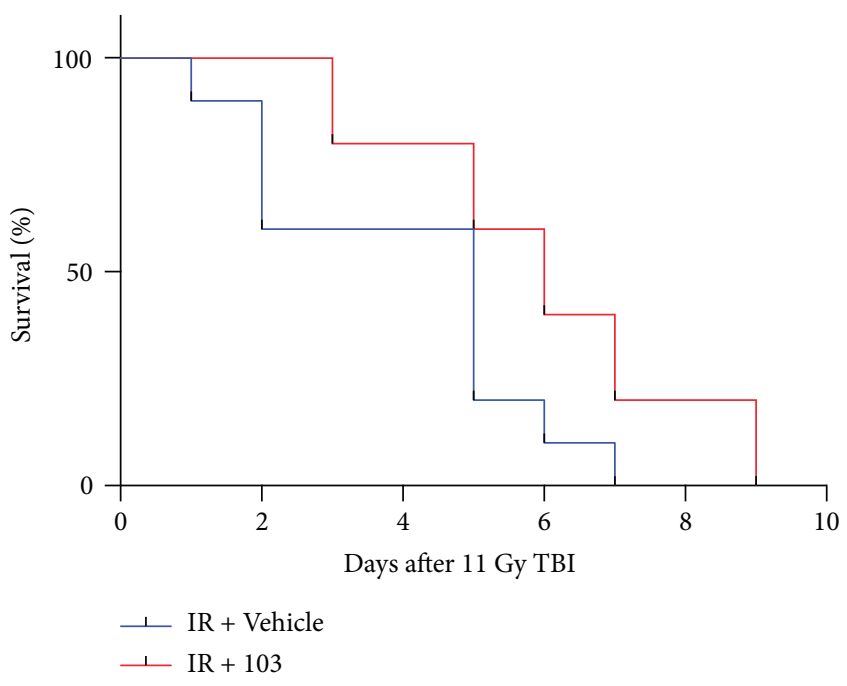

(b)

Figure 2: XH-103 enhances the survival rate of mice after TBI. Kaplan-Meier survival analysis of mice exposed to $9.0 \mathrm{~Gy}$ or $11.0 \mathrm{~Gy}$ TBI. (a) Three doses of XH-103-treated mice show reduced mortality following lethal doses of TBI (9.0 Gy) within 13 days, compared with IR + vehicle group $100 \%$ mortality within 5 days $(p<0.05, n=10$ per group). (b) The Kaplan-Meier survival curve of vehicle- and XH-103-treated mice ( $p<0.05, n=10$ per group) after 11.0 Gy total body irradiation. The data were expressed as the percent of surviving mice.

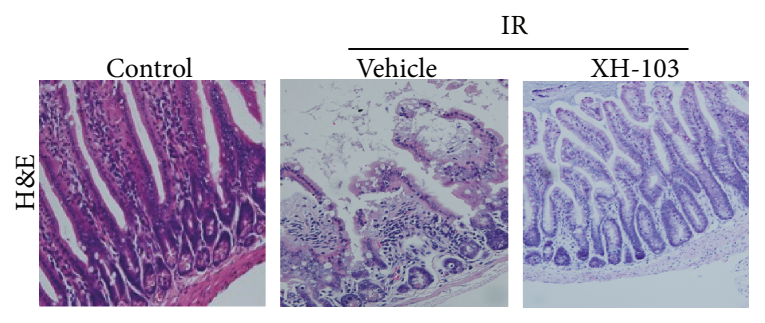

(a)

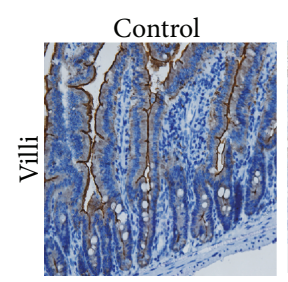

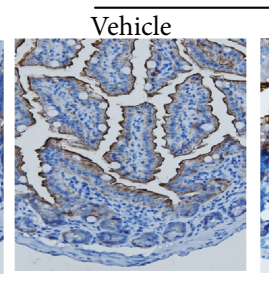

(c)

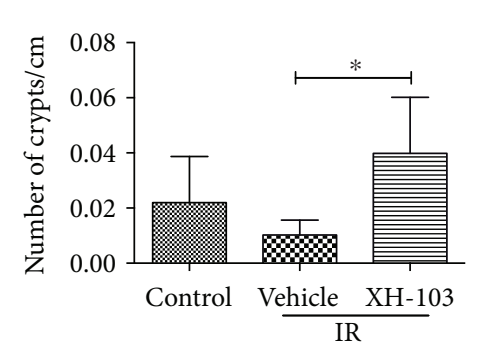

(b)

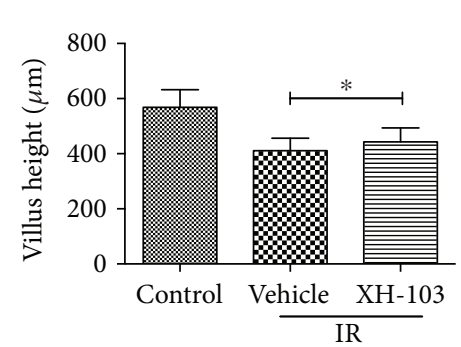

(d)

FIGURE 3: XH-103 protects the intestinal morphology of mice after TBI. (a) Representative images showing the structure in cross sections of the small intestine with H\&E stain. (b) Histogram showing the number of crypts. (c) Immunohistochemistry images showing the expression of villi. (d) Histogram demonstrating villus length in intestinal section from the control group, NS-treated group, and XH103-treated group. The results are represented as mean \pm SEM, $n=5$ mice per group. ${ }^{*} p<0.05$. Scale bar: $100 \mu \mathrm{m}$ and $50 \mu \mathrm{m}$.

survival rate of mice compared with the vehicle-treated group. In the following study, there was $80 \%$ mortality in vehicle-treated mice within 6 days of $11.0 \mathrm{~Gy}$ TBI (Figure 2(b)), compared with XH-103-treated mice having $60 \%$ survival, suggesting that $\mathrm{XH}-103$ may have a protective effect on RIGS in mice. These results indicate that XH-103 effectively mitigates the TBI-induced lethality in mice.

3.3. XH-103 Reduces the Damages of Intestinal Morphology in Mice after TBI. To determine the effect of XH-103 on 

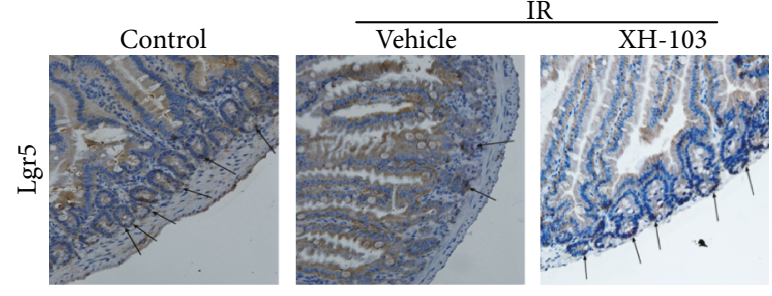

(a)

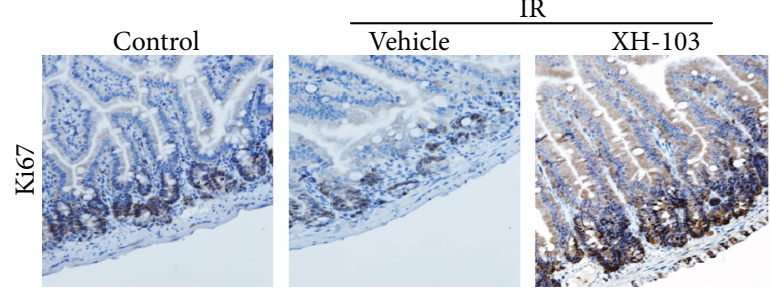

(c)

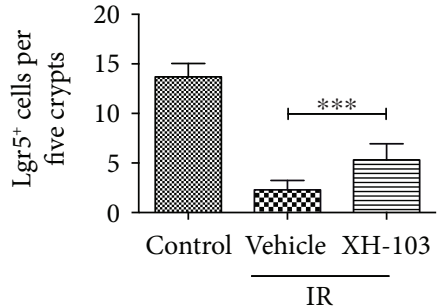

(b)

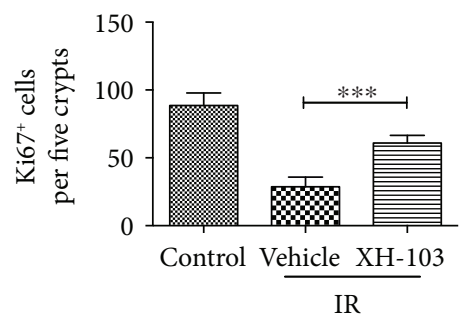

(d)

FIgURE 4: XH-103 increases the proliferation and differentiation of the Lgr $5^{+}$small intestine after TBI. The small intestinal sections were analyzed by IHC. (a) Photomicrograph of Lgr5 immunostaining section of the control, IR + vehicle, and IR+ 103 group. (b) Histogram showing Lgr5-positive cells that were quantified in five crypts per section. (c) Immunostaining images showing quantitative analysis of Ki67 expression of intestinal crypts. (d) Histogram demonstrating Ki67-positive cells that were counted in five crypts per section. The results are represented as mean $\pm \mathrm{SEM}, n=5$ mice per group. ${ }^{* * *} p<0.005$. Scale bar: $50 \mu \mathrm{m}$.

radiation-induced intestinal injuries, the morphological changes of mouse small intestine are shown in Figure 3. At $3 \mathrm{~d}$ after $9.0 \mathrm{~Gy}$ TBI, the irradiated mice showed significantly shorter villous length and fewer crypts than the control group $(p<0.05)$. In comparison to mice in the IR group, XH-103treated mice showed more survival crypts and increased villus height $(p<0.05)$. The expression of villi ${ }^{+}$enterocyte was also decreased by IR (Figure 3(c)) then was significantly increased by $\mathrm{XH}-103$ compared to mice in the IR group. These results indicate that $\mathrm{XH}-103$ treatment can prevent postradiation damage of the intestinal crypt-villus structure of mice.

3.4. XH-103 Enhances Lgr5 ${ }^{+}$ISC Survival and Maintains the Regeneration of Intestinal Cells after TBI. To evaluate the effect of XH-105 on the proliferation and differentiation ability of crypt cells, Lgr5 and Ki67 were identified by immunohistochemistry staining. $\operatorname{Lgr}^{+}$intestinal stem cells are indispensable for intestinal regeneration following radiation [11]. The numbers of Lgr5 ${ }^{+}$ISCs were significantly increased in $\mathrm{XH}-103$-treated mice than in the IR group (Figures 4(a) and 4(b)). Similarly, the numbers of $\mathrm{Ki}^{+} 7^{+}$-positive cells in $\mathrm{XH}$-103-treated mice were also markedly higher than those of mice in the IR group (Figures 4(c) and 4(d)). These results indicate that $\mathrm{XH}-103$ is helpful to maintain differentiation and proliferation ability of intestinal crypt cells.

3.5. XH-103 Decreases Apoptosis of the Small Intestine after TBI. To analyze the role of XH-103 in small intestine apoptosis after TBI, we evaluated the apoptosis by TUNEL assay
(Figures 5(a) and 5(b)). Compared to the control, more apoptosis cells were observed in the IR group, while XH-103 decreased the apoptosis cells. To further validate our observations, we also determined caspase- 8 and caspase- 9 expression in small intestine (Figures 5(c) and 5(e)). The similar results were observed. The expressions of caspase- 8 and caspase- 9 in the XH-103 group were decreased than those in the IR group. These data suggest that XH-103 treatment could decrease the apoptosis cells and protect the irradiationinduced intestinal injuries.

3.6. XH-103 Attenuates DNA Damage of the Small Intestine after TBI. To determine whether XH-103 treatment could reduce TBI-induced DNA damage, we analyzed the expression of histone $\mathrm{H} 2 \mathrm{AX}$ phosphorylation, which has been widely used as a marker for DNA double-strand breaks (DSBs). As demonstrated in Figure 6, there was an increase in $\gamma \mathrm{H} 2 \mathrm{AX}$ of intestinal sections from the IR group compared with the control group. XH-103 treatment decreased H2AX phosphorylation in intestinal sections compared with vehicle-treated mice after $9.0 \mathrm{~Gy}$ TBI. The result indicated that $\mathrm{XH}-103$ could reduce IR-induced DNA damage to the small intestine.

3.7. XH-103 Protects the Small Intestine against RadiationInduced Injury at Least in Part via p53 Pathway. To investigate the mechanisms on how $\mathrm{XH}-103$ protects against the radiation-induced intestinal injuries, we determine the expression of p53 by immunofluorescence analysis (Figure 7(a)). Radiation activates p53 in the GI epithelium, 

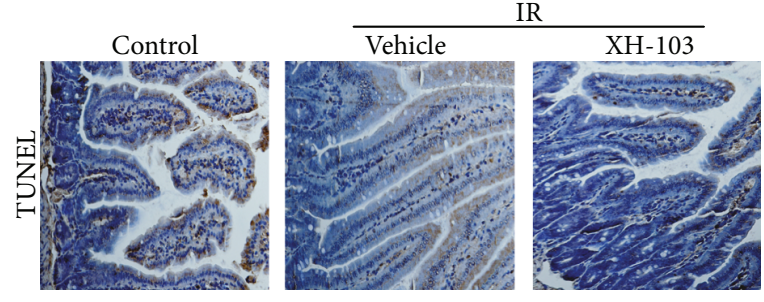

(a)
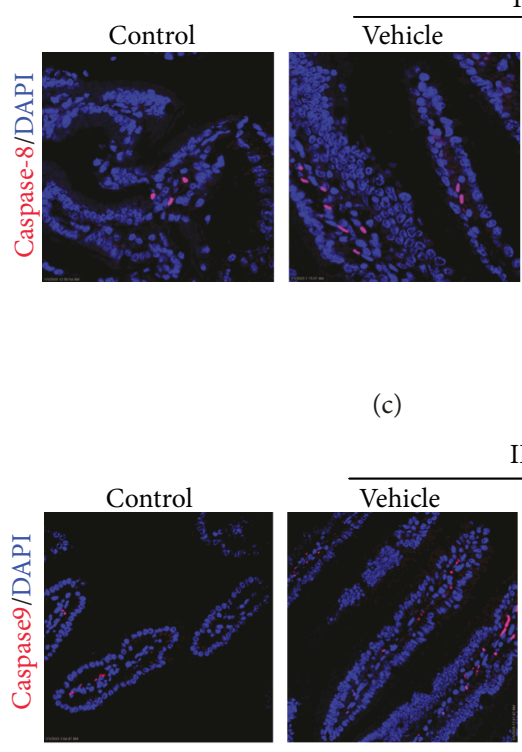

(c)

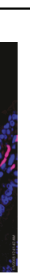

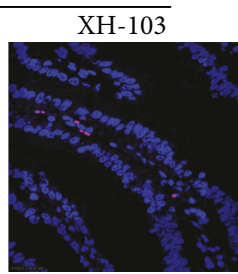

(e)

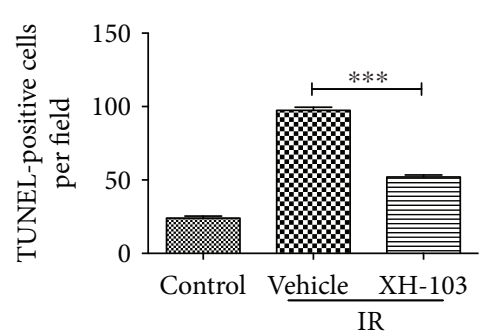

(b)

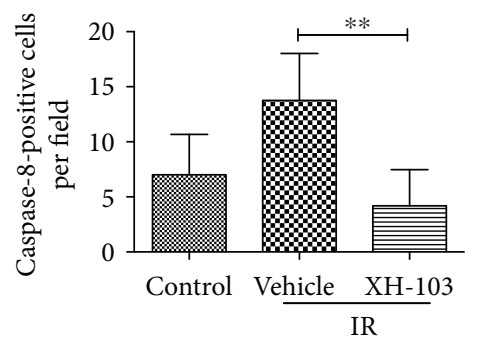

(d)

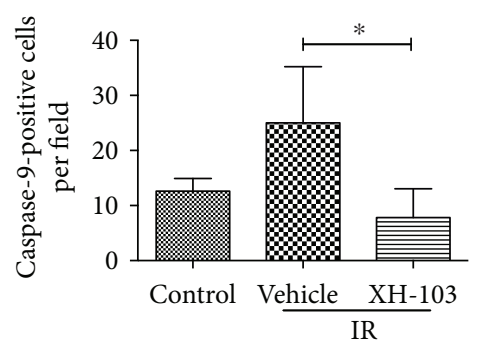

(f)

Figure 5: XH-103 reduces the apoptosis of the small intestine after TBI. (a) Apoptosis was assayed by TUNEL staining. (b) The number of TUNEL-positive cells was quantified per field. The paraffin-embedded sections of the small intestine were analyzed by immunofluorescence. (c) Representative DAPI and caspase-8-staining images of the small intestine (red, caspase-8; blue, DAPI). (d) Caspase-8-positive cells in a single field of view were quantified. (e) Photomicrograph of caspase-9-staining images of the small intestine (red, caspase-9; blue, DAPI). (f) Bar graph showing quantitative analysis of caspase-9-positive cells per field of view. The results are represented as mean \pm SEM, $n=5$ mice per group. ${ }^{*} p<0.05,{ }^{* *} p<0.01,{ }^{* * *} p<0.005$. Scale bar: $50 \mu \mathrm{m}$ and $10 \mu \mathrm{m}$.

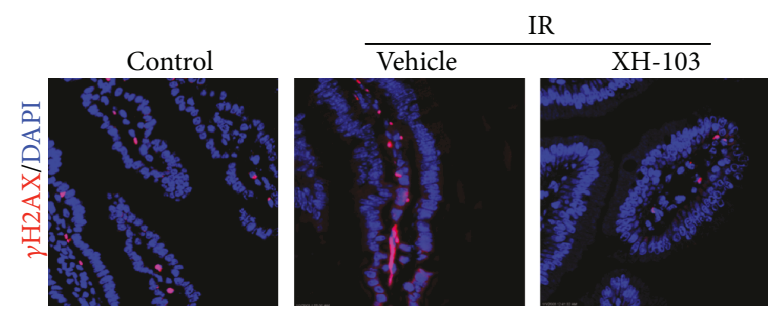

(a)

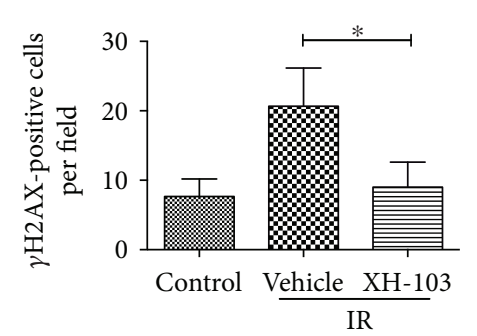

(b)

FIGURE 6: XH-103 attenuates DNA damage of mice after TBI. The small intestines of control mice, vehicle-treated mice, and XH-103-treated mice were obtained at $3 \mathrm{~d}$ after 9.0 Gy TBI. (a) Representative immunofluorescence images for the expression of $\gamma \mathrm{H} 2 \mathrm{AX}$ of the small intestines (red, $\gamma \mathrm{H} 2 \mathrm{AX}$; blue, DAPI). (b) Histogram demonstrating quantitative analysis of $\gamma \mathrm{H} 2 \mathrm{AX}$-positive cells per view field. The results are represented as mean \pm SEM, $n=5$ mice per group. ${ }^{*} p<0.05$. Scale bar: $10 \mu \mathrm{m}$. 


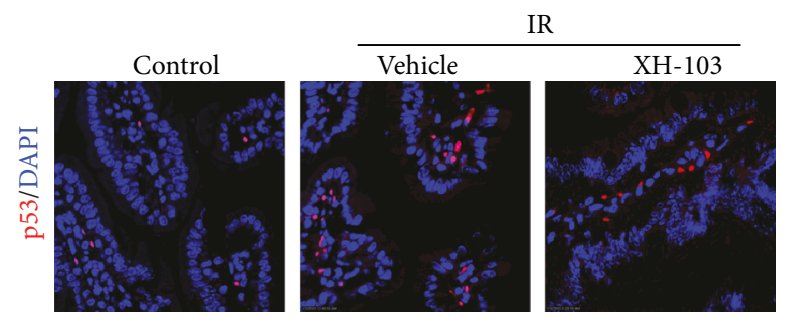

(a)

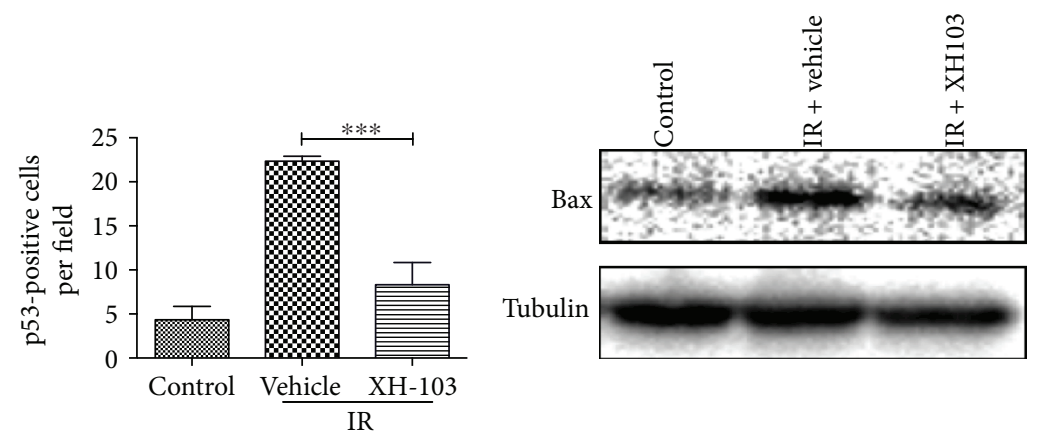

(b)

(c)

FIGURE 7: XH-103 decreases the expression of p53 and Bax after TBI. The small intestinal sections of the control, IR + vehicle, and IR+ 103 mice were gained at $3 \mathrm{~d}$ after $9.0 \mathrm{~Gy}$ TBI. (a) Representative immunofluorescence images for the expression of p53 of the small intestines (red, p53; blue, DAPI). (b) Histogram showing quantitative analysis of p53-positive cells per field of view. (c) Western blot for Bax and tubulin in the intestinal crypts from non-IR mice, vehicle-treated mice, and XH-103-treated mice at $3 \mathrm{~d}$ after $9.0 \mathrm{~Gy}$ TBI. The results are represented as mean \pm SEM, $n=5$ mice per group. ${ }^{* * *} p<0.005$. Scale bar: $10 \mu \mathrm{m}$.

and p53-mediated apoptosis has been implicated in regulating the intestinal radiation injuries $[12,13]$. We also evaluated the expression of Bax in the small intestine crypts by Western blotting at $3 \mathrm{~d}$ after $9.0 \mathrm{~Gy}$ TBI (Figure $7(\mathrm{c})$ ). IR increased the expression of p53 in the small intestine compared with the control group. In contrast, mice treated with $\mathrm{XH}-103$ downregulate the expression of p53 and Bax (Figures 7(b) and $7(\mathrm{c})$ ). These findings suggest that $\mathrm{XH}-103$ protects the small intestine from IR at least by $\mathrm{p} 53$ pathway.

\section{Discussion}

The development of the effective method and drug to mitigate the radiation-induced intestinal injuries is an important area in cancer therapy, nuclear accident, and terrorism. Many studies have reported that Chinese herbal medicine or extracts may reduce TBI-induced injuries in the brain, esophagus, and hematopoietic system of irradiated animals [14-18]; the study of protective drugs on IR-induced intestinal injuries still needs to be improved. In the present study, we synthesized a new compound $\mathrm{XH}-103$ and evaluated the protective effects on radiation-induced intestinal injuries.

In this study, we observe that XH-103 improved the survival rate of mice exposed to the lethal dose TBI, which indicates that $\mathrm{XH}-103$ could protect the mice from irradiation. Under physiological conditions, epithelial homeostasis is maintained by proliferative cells in crypts, and the small intestinal crypt cells are particularly sensitive to IR due to their high proliferative rate [19]. The intestinal epithelium is one of the most rapidly self-renewing organizations in mammals, which is continuously renewed by intestinal epithelium stem cells (IESCs) located in the crypts. Intestinal epithelium cell renewal is identified by expression of Lgr5 $[20,21]$. We found that the numbers of Lgr5 ${ }^{+}$intestinal stem cells were increased in the XH-103 group after 9.0 Gy TBI, and the $\operatorname{Lgr} 5^{+}$intestinal stem cells differentiated into more Paneth cells and villus cells. Thus, $\mathrm{XH}-103$ may play the protective role on IR-induced intestinal injuries by improving the proliferation and differentiation of $\operatorname{Lgr} 5^{+}$intestinal stem cells. The increased expression of Ki67, another proliferative marker in the small intestine, in the XH-103 mice also suggested the protective effects of XH-103 on the intestinal radiation injury. After radiation, various degrees of villus blunting and fusion, villous epithelial cell attenuation and hypertrophy, and severe loss of crypts may occur, leading to destruction of epithelial cell homeostasis and epithelial integrity [13]. Incomplete epithelial cells cannot easily maintain intestinal absorption and defense functions. Our results demonstrated that the intestinal crypt-villus structure from the XH-103-treated mice was well preserved after 9.0 Gy TBI. These results indicate that XH-103 may have a protective effect on irradiation-induced intestinal injury.

Apoptosis is programmed cell death that involves the controlled breakdown of intracellular components. Many studies have shown that IR induced tissue damage, such as small intestinal injuries, with increasing apoptosis cells [22-24]. Caspases are a family of genes important for maintaining homeostasis through regulating apoptosis and inflammation $[25,26]$. Caspases involved in apoptosis have been subclassified by their mechanism of action, initiator caspase (caspase-8 and -9) and executioner caspase (caspase-3, 6 , and 7 ). In this study, we investigated that treatment 
with $\mathrm{XH}-103$ reduces the apoptosis cells compared with the IR group. The expression of caspase- 8 and caspase- 9 in the small intestines of $\mathrm{XH}-103$ was also decreased compared to that of the IR group. These results show the inhibitory effects of XH-103 on radiation-induced apoptosis.

Radiation induces DNA damages [27] and destroys the expression of proteins in cells [28], activating p53 $[23,27,29,30]$. H2AX phosphorylation is an indicator for quantifying DNA double-strand breaks [31-33]. In this study, we found that the expression of $\gamma \mathrm{H} 2 \mathrm{AX}$ was decreased in the XH-103-treated mice compared with the vehicletreated mice.

It is well known that p53 activates genes that regulate cell cycle checkpoints, DNA damage and repair, and apoptosis [34-36]. p53 can promote apoptosis through interactions with $\mathrm{Bcl}-2$ family proteins in the cytoplasm. Studies reported that $\mathrm{Bax}^{-/-}$and $\mathrm{Bakl}^{-/-}$mice reduced the epithelial cell apoptosis exposure to irradiation [37, 38]. Therefore, we examined whether XH-103 inhibits apoptosis by p53 pathway. For these experiments, treatment with XH-103 could decrease the level of p53 and Bax expression. The data suggested that $\mathrm{XH}-103$ might mitigate the radiation-induced intestinal injuries by p53-dependent apoptosis pathway.

Our studies synthesize a new compound XH-103 and show protective effects of $\mathrm{XH}-103$ against radiation-induced intestinal injury. The results also suggest that $\mathrm{XH}-103$ may attenuate radiation-induced intestinal damage via the $\mathrm{p} 53$ pathway. However, XH-103 is a novel compound that needs further optimization.

\section{Data Availability}

The data used to support the findings of this study are available from the corresponding author upon request.

\section{Conflicts of Interest}

The authors declare that they have no conflicts of interest.

\section{Authors' Contributions}

Deguan Li and Hongqi Tian conceived and designed the experiments. Ying Cheng and Hongqi Tian designed and synthesized the new compound XH-103. Deguan Li, Yinping Dong, Qinlian Hou, and Jing Wu carried out the follow-up experiments, analyzed the data, and interpreted the results. Deguan Li and Yinping Dong contributed to data analysis and manuscript preparation. Yinping Dong and Ying Cheng contributed equally to this work and are co-first author.

\section{Acknowledgments}

This study was supported by the National Natural Science Foundation of China (no. 81673106, 81601411); the Natural Science Foundation of Tianjin (15JCZDJC35200); Tianjin Health Industry Key Research Projects (15KG138); the innovation team funding (1649) from the Institute of Radiation Medicine, Chinese Academy of Medical Sciences and Peking
Union Medical College, and Fundamental Research Fund for CAMS\&PUMC (2016ZX310199, 2016ZX310070); and CAMS Innovation Fund for Medical Sciences (CIFMS, 2017-I2M-3-019) from the Chinese Academy of Medical Sciences and Peking Union Medical College.

\section{Supplementary Materials}

Figure S1a: ${ }^{1} \mathrm{H}$ NMR spectra of TZ. ${ }^{1} \mathrm{H}$ NMR $(400 \mathrm{MHz}$, DMSO-d6) $\delta$ ppm 7.95-7.85 (m, 2H), 7.68 (s, 1H), 7.58 $(\mathrm{d}, J=8.3 \mathrm{~Hz}, 1 \mathrm{H}), 7.25(\mathrm{~s}, 1 \mathrm{H}), 4.58(\mathrm{dd}, J=52.9,22.8 \mathrm{~Hz}$, $10 \mathrm{H}), 3.97-3.65$ (m, 10H), 3.14 (d, $J=20.2 \mathrm{~Hz}, 10 \mathrm{H})$. Figure S1b: LC-MS spectra of TZ. LC-MS method. Experiments performed on a Waters 3100 Mass Detector. Chromatographic column: Agilent, ZORBAX, C18 2.1*50 mm $3.5 \mu$. Flow rate: $0.6 \mathrm{~mL} / \mathrm{min}$; mobile phase A: $0.1 \%$ formic acid in water; mobile phase B: $100 \%$ acetonitrile. Gradient elution program: $t=0 \mathrm{~min}, \mathrm{~A} \%=10 \% ; t=5.5 \mathrm{~min}, \mathrm{~A} \%=95 \% ; t=6.5 \mathrm{~min}$, $\mathrm{A} \%=95 \% ; t=7 \mathrm{~min}, \mathrm{~A} \%=10 \% ; t=10 \mathrm{~min}, \mathrm{~A} \%=10 \%$; $R T=4.50 \mathrm{~min}$, MS (ESI, positive ion) $\mathrm{m} / \mathrm{z}: 878.15(\mathrm{M}+1)$. (Supplementary Materials)

\section{References}

[1] N. H. A. Terry and E. L. Travis, "The influence of bone marrow depletion on intestinal radiation damage," International Journal of Radiation Oncology*Biology*Physics, vol. 17, no. 3, pp. 569-573, 1989.

[2] M. E. Berger, D. M. Christensen, P. C. Lowry, O. W. Jones, and A. L. Wiley, "Medical management of radiation injuries: current approaches," Occupational Medicine, vol. 56, no. 3, pp. 162-172, 2006.

[3] P. Monti, J. Wysocki, A. van der Meeren, and N. M. Griffiths, "The contribution of radiation-induced injury to the gastrointestinal tract in the development of multi-organ dysfunction syndrome or failure," The British Journal of Radiology, no. 1, Supplement_27, pp. 89-94, 2005.

[4] D. D. Peebles, C. M. Soref, R. R. Copp, A. L. Thunberg, and W. E. Fahl, "ROS-scavenger and radioprotective efficacy of the new PrC-210 aminothiol," Radiation Research, vol. 178, no. 1, pp. 57-68, 2012.

[5] W. Liu, Q. Chen, S. Wu et al., "Radioprotector WR-2721 and mitigating peptidoglycan synergistically promote mouse survival through the amelioration of intestinal and bone marrow damage," Journal of Radiation Research, vol. 56, no. 2, pp. 278-286, 2015.

[6] P. Bansal, P. Paul, A. Kunwar et al., "Radioprotection by quercetin-3-O-rutinoside, a flavonoid glycoside - a cellular and mechanistic approach," Journal of Functional Foods, vol. 4, no. 4, pp. 924-932, 2012.

[7] A. R. Bilia, B. Isacchi, C. Righeschi, C. Guccione, and M. C. Bergonzi, "Flavonoids loaded in nanocarriers: an opportunity to increase oral bioavailability and bioefficacy," Food and Nutrition Sciences, vol. 05, no. 13, pp. 1212-1327, 2014.

[8] D. M. Brizel, T. H. Wasserman, M. Henke et al., "Phase III randomized trial of amifostine as a radioprotector in head and neck cancer," Journal of Clinical Oncology, vol. 18, no. 19 , pp. 3339-3345, 2000.

[9] M. M. Mahé, E. Aihara, M. A. Schumacher et al., "Establishment of gastrointestinal epithelial organoids," Current Protocols in Mouse Biology, vol. 3, no. 4, pp. 217-240, 2013. 
[10] W. Yang, Z. Sun, B. Yang, and Q. Wang, "Nrf2-knockout protects from intestinal injuries in C57BL/6J mice following abdominal irradiation with $\gamma$ rays," International Journal of Molecular Sciences, vol. 18, no. 8, 2017.

[11] C. Metcalfe, N. M. Kljavin, R. Ybarra, and F. J. de Sauvage, " $\mathrm{Lgr} 5^{+}$stem cells are indispensable for radiation-induced intestinal regeneration," Cell Stem Cell, vol. 14, no. 2, pp. 149-159, 2014.

[12] W. Qiu, E. B. Carson-Walter, H. Liu et al., "PUMA regulates intestinal progenitor cell radiosensitivity and gastrointestinal syndrome," Cell Stem Cell, vol. 2, no. 6, pp. 576-583, 2008.

[13] A. J. Merritt, C. S. Potten, C. J. Kemp et al., "The role of p53 in spontaneous and radiation-induced apoptosis in the gastrointestinal tract of normal and p53-deficient mice," Cancer Research, vol. 54, no. 3, pp. 614-617, 1994.

[14] I. Kindekov, M. Mileva, D. Krastev et al., "Radioprotective effect ofRapana thomasianahemocyanin in gamma induced acute radiation syndrome," Biotechnology \& Biotechnological Equipment, vol. 28, no. 3, pp. 533-539, 2014.

[15] L. Lu, Y.-Y. Wang, J.-L. Zhang, D.-G. Li, and A.-M. Meng, "p38 MAPK inhibitor insufficiently attenuates HSC senescence administered long-term after 6 Gy total body irradiation in mice," International Journal of Molecular Sciences, vol. 17, no. 6, p. 905, 2016.

[16] D. Li, Z. Tian, W. Tang et al., "The protective effects of 5 -methoxytryptamine- $\alpha$-lipoic acid on ionizing radiationinduced hematopoietic injury," International Journal of Molecular Sciences, vol. 17, no. 6, p. 935, 2016.

[17] S. Suryavanshi, D. Sharma, R. Checker et al., "Amelioration of radiation-induced hematopoietic syndrome by an antioxidant chlorophyllin through increased stem cell activity and modulation of hematopoiesis," Free Radical Biology \& Medicine, vol. 85, pp. 56-70, 2015.

[18] J. Li, J. Xu, W. Xu et al., "Protective effects of Hong Shan capsule against lethal total-body irradiation-induced damage in Wistar rats," International Journal of Molecular Sciences, vol. 16, no. 8, pp. 18938-18955, 2015.

[19] C. S. Potten and H. K. Grant, "The relationship between ionizing radiation-induced apoptosis and stem cells in the small and large intestine," British Journal of Cancer, vol. 78, no. 8, pp. 993-1003, 1998.

[20] H. Clevers, "Identification of stem cells in small intestine and colon by a single marker gene Lgr5," European Journal of Cancer Supplements, vol. 6, no. 9, p. 1, 2008.

[21] I. Stzepourginski, G. Nigro, J. M. Jacob et al., "CD34 ${ }^{+}$mesenchymal cells are a major component of the intestinal stem cells niche at homeostasis and after injury," Proceedings of the National Academy of Sciences of the United States of America, vol. 114, no. 4, pp. E506-E513, 2017.

[22] H. Zhang, H. Yan, X. Zhou et al., "The protective effects of resveratrol against radiation-induced intestinal injury," $B M C$ Complementary and Alternative Medicine, vol. 17, no. 1, p. 410, 2017.

[23] D. G. Kirsch, P. M. Santiago, E. di Tomaso et al., "p53 controls radiation-induced gastrointestinal syndrome in mice independent of apoptosis," Science, vol. 327, no. 5965, pp. 593-596, 2010.

[24] A. Morita, I. Takahashi, M. Sasatani et al., "A chemical modulator of p53 transactivation that acts as a radioprotective agonist," Molecular Cancer Therapeutics, vol. 17, no. 2, pp. 432-442, 2018.
[25] D. R. Mcllwain, T. Berger, and T. W. Mak, "Caspase functions in cell death and disease," Cold Spring Harbor Perspectives in Biology, vol. 5, no. 4, article a008656, 2013.

[26] A. Negroni, S. Cucchiara, and L. Stronati, "Apoptosis, necrosis, and necroptosis in the gut and intestinal homeostasis," Mediators of Inflammation, vol. 2015, Article ID 250762, 10 pages, 2015.

[27] X. Han, E. Mann, S. Gilbert et al., "Loss of guanylyl cyclase C (GCC) signaling leads to dysfunctional intestinal barrier," PLoS One, vol. 6, no. 1, article e16139, 2011.

[28] X. Sun, Q. Wang, Y. Wang, L. Du, C. Xu, and Q. Liu, "Brusatol enhances the radiosensitivity of A549 cells by promoting ROS production and enhancing DNA damage," International Journal of Molecular Sciences, vol. 17, no. 7, p. 997, 2016.

[29] J. M. Sullivan, L. B. Jeffords, C.-L. Lee, R. Rodrigues, Y. Ma, and D. G. Kirsch, "p21 protects "super p53" mice from the radiation-induced gastrointestinal syndrome," Radiation Research, vol. 177, no. 3, pp. 307-310, 2012.

[30] B. J. Leibowitz, W. Qiu, H. Liu, T. Cheng, L. Zhang, and J. Yu, "Uncoupling p53 functions in radiation-induced intestinal damage via PUMA and p21," Molecular Cancer Research, vol. 9, no. 5, pp. 616-625, 2011.

[31] Y. Wang, A. Meng, H. Lang et al., "Activation of nuclear factor $\kappa \mathrm{B}$ in vivo selectively protects the murine small intestine against ionizing radiation-induced damage," Cancer Research, vol. 64, no. 17, pp. 6240-6246, 2004.

[32] Y. Shiloh, "ATM and related protein kinases: safeguarding genome integrity," Nature Reviews. Cancer, vol. 3, no. 3, pp. 155-168, 2003.

[33] M. Podhorecka, A. Skladanowski, and P. Bozko, "H2AX phosphorylation: its role in DNA damage response and cancer therapy," Journal of Nucleic Acids, vol. 2010, Article ID 920161, 9 pages, 2010.

[34] S. S. Foster, S. De, L. K. Johnson, J. H. J. Petrini, and T. H. Stracker, "Cell cycle- and DNA repair pathway-specific effects of apoptosis on tumor suppression," Proceedings of the National Academy of Sciences of the United States of America, vol. 109, no. 25, pp. 9953-9958, 2012.

[35] J. R. Jeffers, E. Parganas, Y. Lee et al., "Puma is an essential mediator of p53-dependent and -independent apoptotic pathways," Cancer Cell, vol. 4, no. 4, pp. 321-328, 2003.

[36] M.-J. Halaby, Y. Li, B. R. Harris et al., "Translational control protein 80 stimulates IRES-mediated translation of p53 mRNA in response to DNA damage," BioMed Research International, vol. 2015, Article ID 708158, 9 pages, 2015.

[37] M. Garcia-Barros, F. Paris, C. Cordon-Cardo et al., "Tumor response to radiotherapy regulated by endothelial cell apoptosis," Science, vol. 300, no. 5622, pp. 1155-1159, 2003.

[38] A. J. Merritt, T. D. Allen, C. S. Potten, and J. A. Hickman, "Apoptosis in small intestinal epithelia from p53-null mice: evidence for a delayed, p53-indepdendent G2/M-associated cell death after $\gamma$-irradiation," Oncogene, vol. 14 , no. 23, pp. 2759-2766, 1997. 


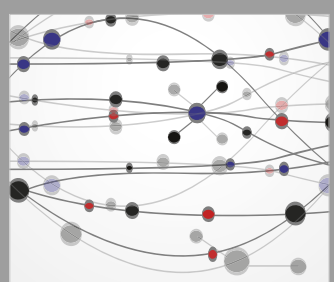

The Scientific World Journal
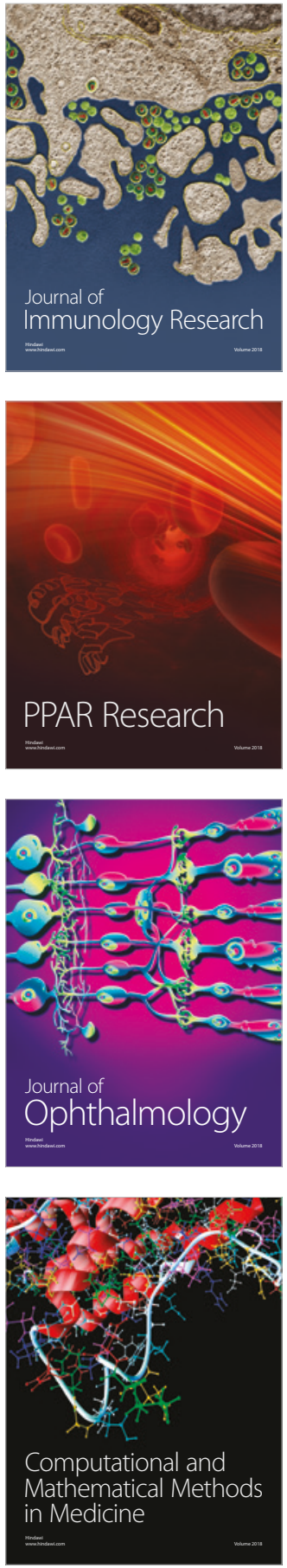

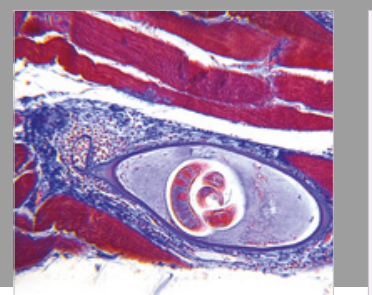

Gastroenterology Research and Practice

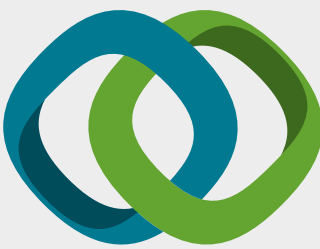

\section{Hindawi}

Submit your manuscripts at

www.hindawi.com
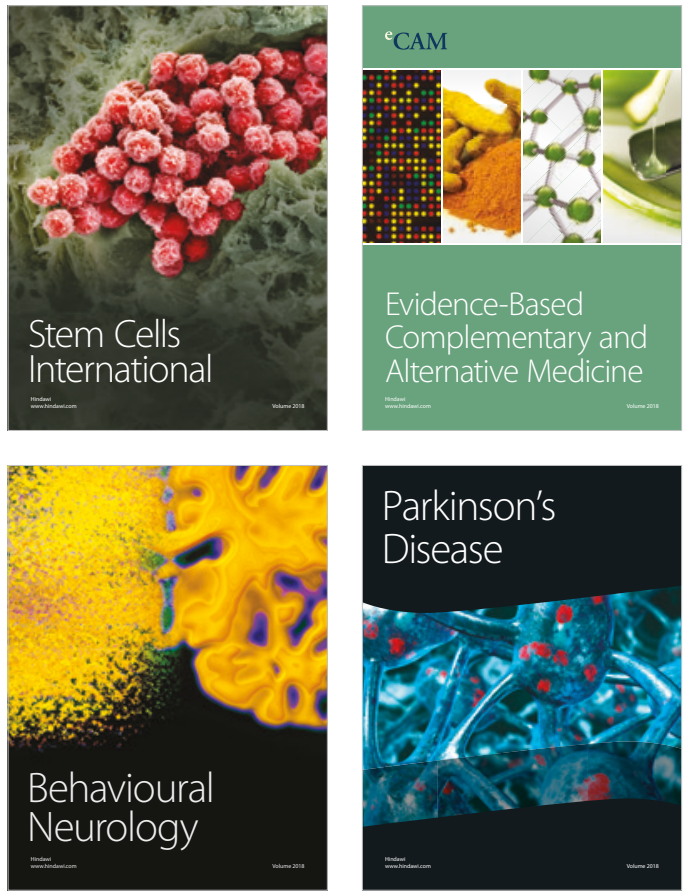

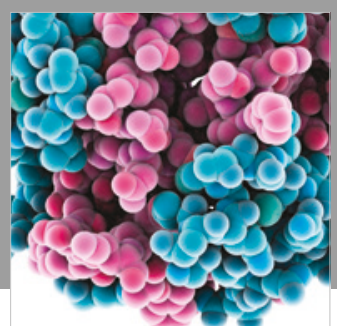

ournal of

Diabetes Research

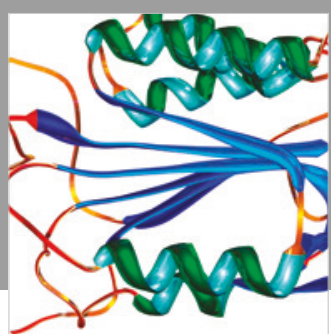

Disease Markers
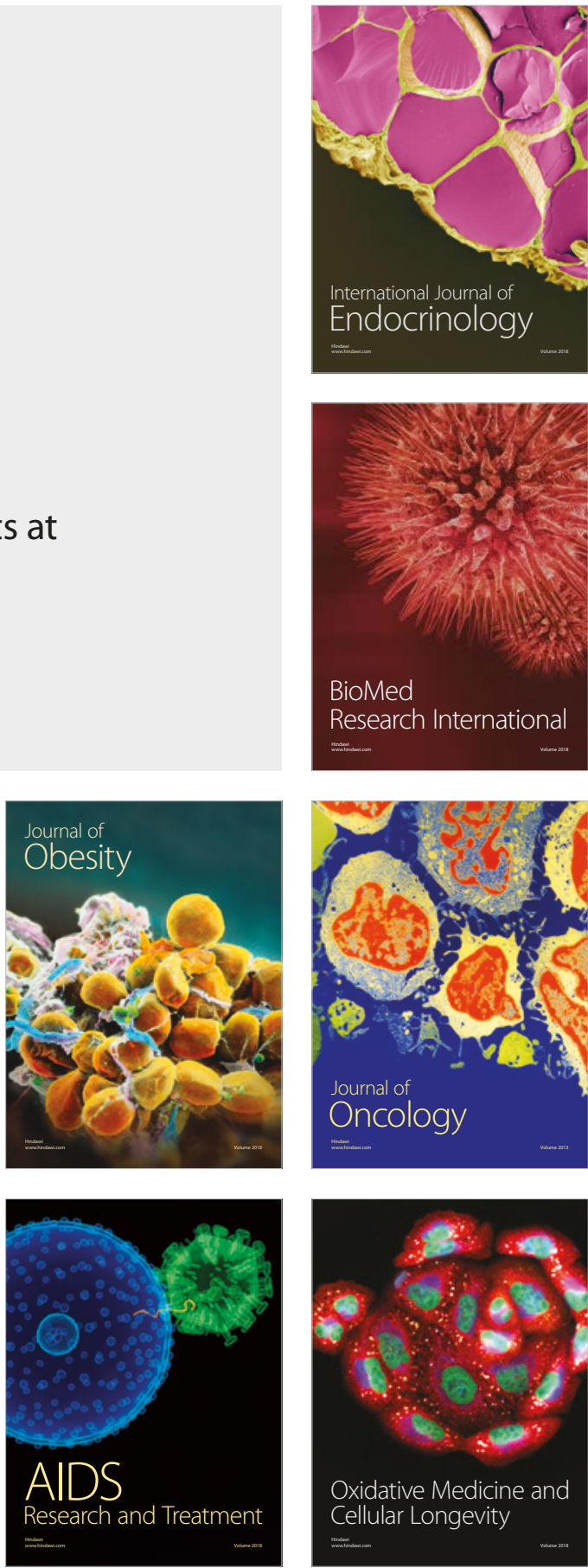